\title{
In situ nuclear magnetic resonance response of permafrost and active layer soil in boreal and tundra ecosystems
}

\author{
M. Andy Kass ${ }^{1, a}$, Trevor P. Irons ${ }^{2}$, Burke J. Minsley ${ }^{1}$, Neal J. Pastick ${ }^{3,4}$, Dana R. N. Brown ${ }^{5}$, and Bruce K. Wylie \\ ${ }^{1}$ Crustal Geophysics and Geochemistry Science Center, US Geological Survey, Denver, CO 80225, USA \\ ${ }^{2}$ Department of Civil and Environmental Engineering, Energy and Geoscience Institute, \\ University of Utah, Salt Lake City, UT 84112, USA \\ ${ }^{3}$ Stinger Ghaffarian Technologies, Inc., Sioux Falls, SD 57198, USA \\ ${ }^{4}$ Department of Forest Resources, University of Minnesota Twin Cities, St. Paul, MN 55108, USA \\ ${ }^{5}$ Institute of Arctic Biology, University of Alaska Fairbanks, Fairbanks, AK 99775, USA \\ ${ }^{6}$ Earth Resources Observation and Science Center, US Geological Survey, Sioux Falls, SD 57198, USA \\ anow at: Hydrogeophysics Group, Aarhus University, 8000 Aarhus, Denmark
}

Correspondence: M. Andy Kass (andy.kass@geo.au.dk)

Received: 31 October 2016 - Discussion started: 23 January 2017

Revised: 26 July 2017 - Accepted: 15 October 2017 - Published: 14 December 2017

\begin{abstract}
Characterization of permafrost, particularly warm and near-surface permafrost which can contain significant liquid water, is critical to understanding complex interrelationships with climate change, ecosystems, and disturbances such as wildfires. Understanding the vulnerability and resilience of permafrost requires an interdisciplinary approach, relying on (for example) geophysical investigations, ecological characterization, direct observations, remote sensing, and more. As part of a multiyear investigation into the impacts of wildfires on permafrost, we have collected in situ measurements of the nuclear magnetic resonance (NMR) response of the active layer and permafrost in a variety of soil conditions, types, and saturations. In this paper, we summarize the NMR data and present quantitative relationships between active layer and permafrost liquid water content and pore sizes and show the efficacy of borehole NMR (bNMR) to permafrost studies. Through statistical analyses and synthetic freezing simulations, we also demonstrate that borehole NMR is sensitive to the nucleation of ice within soil pore spaces.
\end{abstract}

\section{Introduction}

Permafrost is an integral part of high-latitude ecosystems, underlying nearly $24 \%$ of the exposed land area in the Northern Hemisphere (Zhang et al., 1999). Much of this permafrost is considered "warm" or "vulnerable", where the temperature is within $5^{\circ}$ of the freezing point. For example, Henry and Smith (2001) estimate that approximately $54 \%$ of the permafrost in Canada exists between -5 and $0{ }^{\circ} \mathrm{C}$. This warm permafrost is often discontinuous and quite vulnerable to changes in air temperature, snow accumulation, and surface disturbance (Osterkamp et al., 2000; Hinzman et al., 2005; Jorgenson et al., 2010).

Permafrost thaw can have substantial influences on terrain and ecosystems, with consequences we are only beginning to understand and quantify. Perhaps most notable is the liberation and mobilization of vast quantities of carbon sequestered in near-surface permafrost. This reservoir can become bioavailable and is estimated to be on the order of $20-60 \mathrm{~kg} \mathrm{~m}^{-3}$ (Brown et al., 2003; Zimov et al., 2006). This represents the potential for positive feedbacks to climate warming (Schuur et al., 2015). Tarnocai et al. (2009) estimate that half of all soil organic carbon exists within permafrost, with Hugelius et al. (2014) estimating a slightly lower value. However, equally significant is the interrelationship between boreal forests (taiga) and discontinuous per- 
mafrost. These forests compose at least half of all the land area underlain by permafrost, and degradation of ice-rich permafrost can have severe consequences on these ecosystems, resulting in the conversion of forestland into bogs or fens in lowland environments (Osterkamp et al., 2000; Lara et al., 2016). Similar water impoundment can occur with subsidence in tundra ecosystems. Degradation can fundamentally alter local and regional hydrology, with divergent consequences depending on permafrost ice content, topography, and soil texture (Jorgenson et al., 2013). Extreme effects such as thermokarst-related subsidence of up to $6 \mathrm{~m}$ (e.g., Yoshikawa and Hinzman, 2003) are possible. Catastrophic events such as wildfires can initiate or exacerbate permafrost degradation by combustion of surface organics, thereby increasing soil heat flux (e.g., Yoshikawa and Hinzman, 2003; Minsley et al., 2016b). All of these effects lead to increased ecosystem stress through increased vulnerability and altered long-term forest communities. This list is far from complete; we refer the reader to Hinzman et al. (2005) for a comprehensive treatment.

With such a complex relationship between permafrost and the environment - potentially leading to drastic changes in ecosystems in a warming climate - it is clearly critical to understand the characteristics of vulnerable permafrost, especially in situ. Changes to the structure and composition of both frozen and unfrozen highly saturated soils due to extraction from the ground can alter sample results in laboratory tests, and understanding in situ characteristics will allow for repeat and continuous monitoring. The hydrology of permafrost is particularly interesting, as significant unfrozen water can remain in permafrost at surprisingly low temperatures, which is well below what is considered warm permafrost (e.g., Williams, 1964; Kuroda, 1985; Davis, 2001; Kleinberg and Griffin, 2005; Watanabe and Wake, 2009).

Previous studies have successfully investigated water contents in permafrost using nuclear magnetic resonance (NMR) in drill cores (e.g., Kleinberg and Griffin, 2005) or in constructed substrates (e.g., Watanabe and Mizoguchi, 2002; Sparrman et al., 2004). Attempts at borehole NMR (bNMR) measurement in situ have generally been performed in oil field applications and have failed due to degradation of the permafrost as a consequence of the drilling mud thermal interaction and infiltration (Kleinberg and Griffin, 2005). Recent advances in miniaturization and improvements in instrumentation of borehole NMR tools have allowed measurements to be made in drill holes that do not require drilling mud.

In this paper, we present the results of borehole nuclear magnetic resonance surveys as part of a larger multiyear interdisciplinary study in Alaska (Minsley et al., 2016b) to investigate water content and porosity characteristics of the permafrost and active layer in situ, without requiring core analysis. We observe significant quantities of liquid water within near-surface (upper $3 \mathrm{~m}$ ) permafrost and describe the distribution of that water as a function of apparent pore size.
The dataset includes measurements from discontinuous and continuous permafrost in boreal forest and tundra ecosystems, as well as directly within a known ice wedge. Performing bNMR measurements in both the active layer and in permafrost, as well as in disturbed areas and identical undisturbed terrain, allows us to investigate the hydrologic characteristics while controlling for variable geology and soil types. We believe this to be the first successful bNMR dataset in permafrost of its type.

\subsection{Field area}

This study contains data primarily from the boreal forests of Alaska, though a few data points were acquired farther north in tundra regions (Fig. 1). Each survey location was selected to span the boundary between the burned landscape from a wildfire and the unburned forest at a variety of burn ages, terrains, and permafrost continuity (Pastick et al., 2015). In total, 37 boreholes were sampled across 25 site locations, covering a transect of over $900 \mathrm{~km}$.

\section{Methods}

At each field site, one or more boreholes were drilled along a transect and immediately logged with a borehole NMR probe. Electrical resistivity tomography was also measured along the transect, along with data on soil type and depth as well as vegetation type. Borehole temperature data were acquired in a few selected locations. Transects were constructed to cross from wildfire-burned terrain into unburned terrain. All data were acquired in late summer to early fall at maximal seasonal thaw.

\subsection{Borehole construction}

Holes were drilled either manually with a soil auger (5.7 $\mathrm{cm}$ diameter) or using a gasoline-powered auger with an ice bit ( $6.35 \mathrm{~cm}$ diameter). At five sites (site names prepended with "CCHRC") at the Cold Climate Housing Research Center at the University of Alaska Fairbanks (www.cchrc.org), boreholes drilled with a rotary Geoprobe (Geoprobe Systems, Salina, Kansas, USA) were logged between $1 \mathrm{~h}$ and several days after drilling.

Both manual and gas augers successfully drilled through the active layer and permafrost to depths of up to $2.75 \mathrm{~m}$ while minimally disturbing the structure of the surrounding medium. Figure 2 demonstrates the efficacy of using a gasoline auger - ice is visible along the borehole walls showing the limited thermal interaction between the bit/drilling activity and the medium.

In some cases, heavy water saturation in the active layer caused the borehole to completely collapse above the permafrost as soon as the auger was removed. Many holes were abandoned in these conditions; where measurements were made, we note that the estimation of the water saturation in 


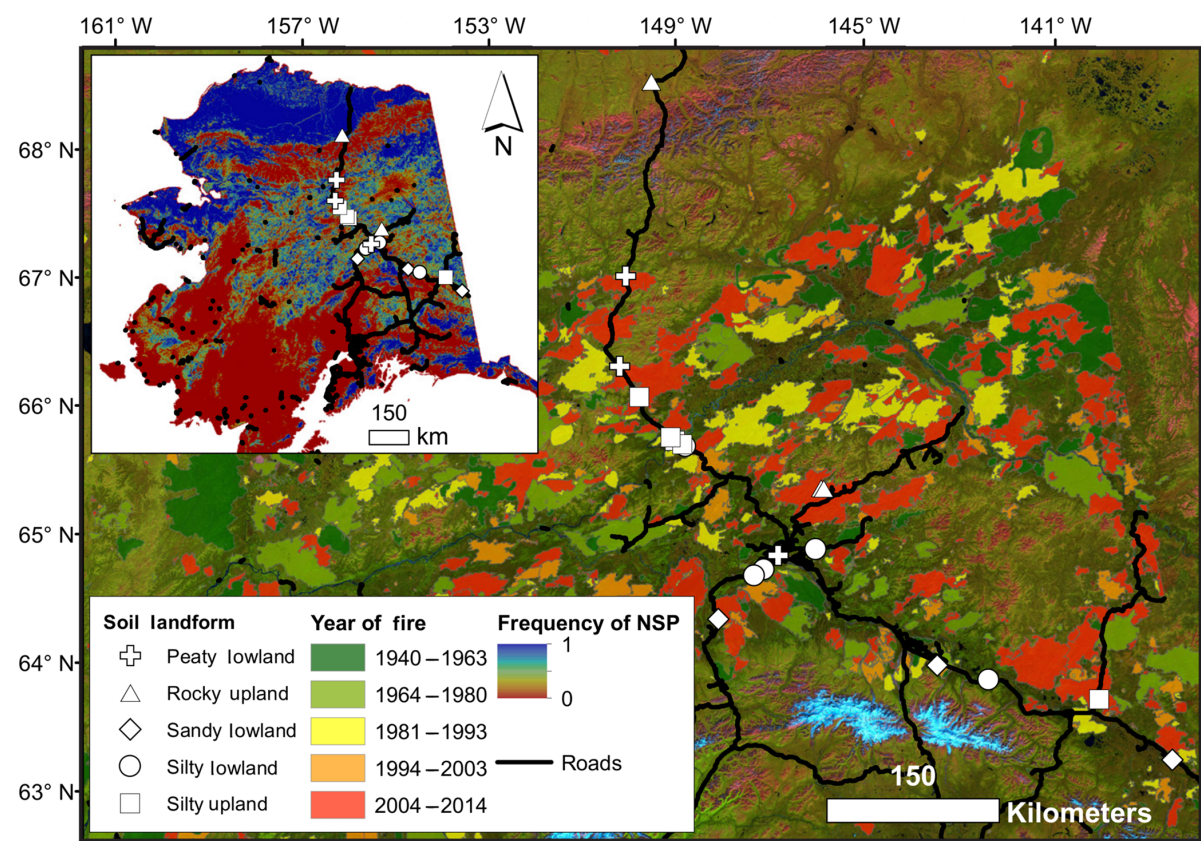

Figure 1. Field study area with wildfire boundaries since 1940 (fire management records available from the Alaska Interagency Coordination Center at https://fire.ak.blm.gov). Study sites are marked with white symbols indicating the predominant soil landform. Inset: state map of Alaska with prediction of near-surface permafrost (Pastick et al., 2015) and site locations.

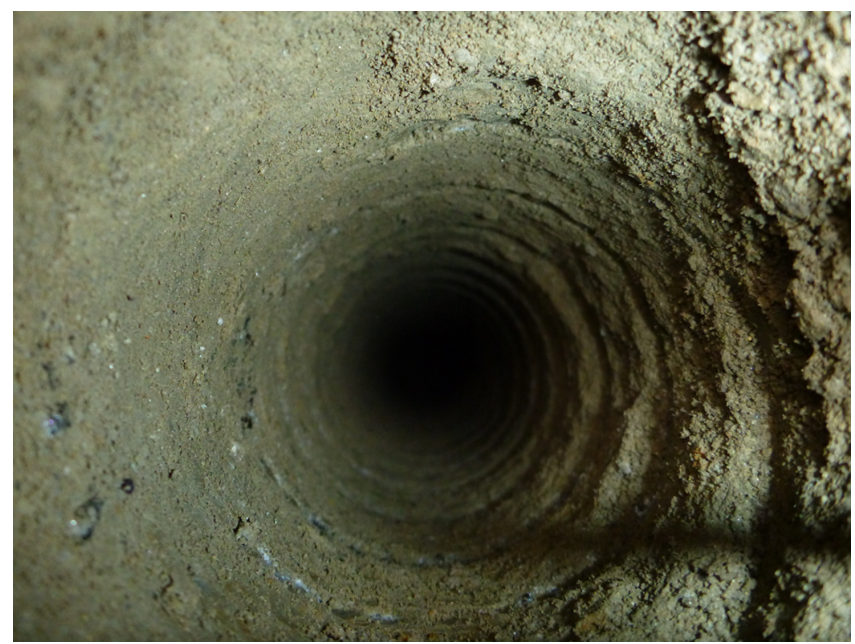

Figure 2. Photo of borehole after completion with gasolinepowered auger. Ice is visible along the walls where the soil was abraded, demonstrating the limited thermal effects of drilling.

the active layer may be high. This effect is most pronounced when the saturation is above 60 to $70 \%$.

\subsection{Data acquisition}

\subsubsection{Borehole NMR}

The nuclear magnetic resonance technique is the only geophysical tool directly sensitive to groundwater. When placed in a magnetic field, the proton in a hydrogen atom tends to precess with an axis parallel to that field. By generating an electromagnetic pulse or sequence of pulses at the Larmor frequency (which is a function of the individual atom's gyromagnetic ratio and the ambient magnetic field), the precession can be tipped. Once tipped, these precessing atoms now also in phase - relax back to their steady state, resulting in a measurable secondary electromagnetic field. The initial amplitude of this decaying secondary field is proportional to the total quantity of water within the volume of investigation. As water molecules move around a pore space (a function of Brownian motion), they have a probability of impacting a pore wall; when they do, they quickly relax and contribute to the measured secondary field at a different decay rate. Therefore, the measured signal is a function of total volumetric water as well as the surface-area-to-volume ratio of the pore (pore size). With ancillary information, hydraulic conductivity can also be estimated (e.g., Kenyon, 1997). These measurements can be made from borehole or surface systems. It may be helpful toward understanding to note that the physics of the NMR geophysical measurement are the same as those of a medical magnetic resonance imaging (MRI) scan.

Originally developed for oilfield investigations in consolidated sandstone, borehole NMR has enjoyed expansion into environmental applications as well over the past decade. The technique has proven useful in unconsolidated aquifers and in a variety of soil types (e.g., Legchenko et al., 2004; Knight et al., 2012; Behroozmand et al., 2015; Parsekian et al., 2015). NMR is also applied to multiphase systems (e.g., 


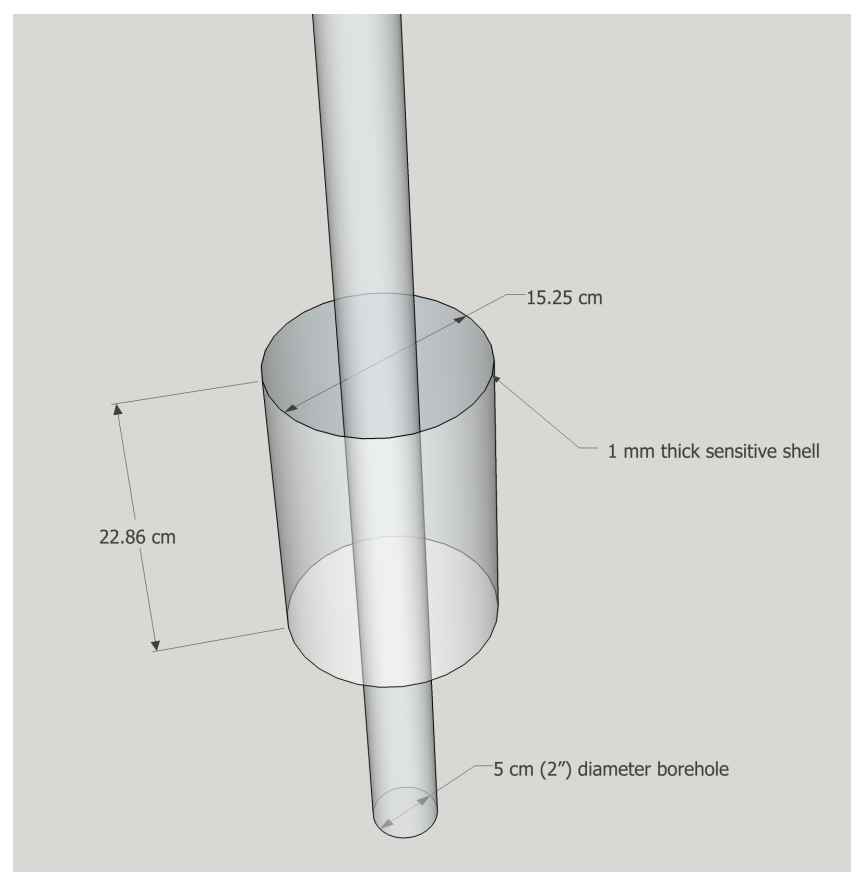

Figure 3. Schematic of the geometry of the sensitive zone. The instrument fits down a $5 \mathrm{~cm}$ borehole and has a vertical sensitive zone of approximately $23 \mathrm{~cm}$. The $1-2 \mathrm{~mm}$ thick sensitive zone is centered about a cylindrical shell approximately $15 \mathrm{~cm}$ in diameter.

water-petroleum, water-air, and now water-ice) with success (e.g., Song, 2010; Parsekian et al., 2013; Walsh et al., 2014).

Borehole data were acquired with a Dart NMR in situ soil moisture probe (Vista Clara, Inc., Mukilteo, Washington, USA). The probe has a diameter of $4.4 \mathrm{~cm}$ with a sensitive zone consisting of a 1-2 mm thick cylindrical shell centered at the middle of the tool with a diameter of $15.3 \mathrm{~cm}$ (well outside the borehole disturbed zone) and a vertical extent of $22.9 \mathrm{~cm}$ (Fig. 3). The relatively light and compact nature of the instrument coupled with the portable augers allows for data acquisition in remote and rough terrain (Walsh et al., 2013).

Within each borehole, the instrument was held at a static depth for the duration of one record, then moved to acquire data at the next desired depth. At each location, the instrument acquired two Carr-Purcell-Meiboom-Gill (CPMG) pulse datasets (Meiboom and Gill, 1958): a long (3 s) record and a "burst mode" with a $0.8 \mathrm{~s}$ record, which are combined to improve the signal-to-noise ratio in the first $0.8 \mathrm{~s}$ of the decay. The long record consisted of 374 echoes with 50 stacks while the burst mode contained 62 echoes and a minimum of 200 stacks. The pulse length was $0.06 \mathrm{~ms}$ with an interpulse delay of $0.8 \mathrm{~ms}$. Because of the background field defined by permanent magnets in the instrument, data were recorded at two fixed frequencies: 426.27 and $478.271 \mathrm{kHz}$ which further improves the signal-to-noise ratio of the resulting measure- ments. Before both field campaigns, the instrument was calibrated by the manufacturer (Walsh et al., 2013). Calibration was found to be satisfactory through measurements of bulk water and air. A total record at one depth takes approximately 5 min to log, depending on number of stacks.

\subsubsection{Other data acquisition}

Coincident with the NMR data, surface direct current (DC) resistivity data were acquired along transects of varying length. This improved the interpretability and confidence of the permafrost depth measurements and revealed subsurface permafrost structure. For this study, the DC data were used to site optimal borehole locations and target depths.

In addition to geophysical data, depth to permafrost was measured with a permafrost probe (a long, thin metal spike driven into the soil). Care was taken to differentiate between seasonal frost and permafrost (both using the permafrost probe and through comparison with the resistivity models later); however, seasonal frost may be represented in the frozen soils data. Organic layer thickness was measured along each geophysical transect.

Each location was classified into one of four soil types: silty, sandy, peaty, or rocky. Terrain was classified as upland or lowland. Clearly, any one field site could exhibit more than one soil type; these classifications reflect the predominant soil present.

In a few sites, temperature probes were installed. Flexible polyethylene (PEX) tubing was inserted as deeply as possible, then temperature was measured with a thermistor after the tubing was allowed to thermally equilibrate.

\subsection{Data processing}

\subsubsection{Borehole NMR}

The NMR data were processed using commercial software (Vista Clara, Inc.) to despike and stack the data and produce estimates of water content and pore size distribution. The data were first culled to remove records contaminated by spikes, then the two pulses at each frequency were combined to form one averaged time series, known as the $T_{2}$ or spin-echo decay. A single $T_{2}$ decay was constructed for each depth at each borehole. The time series can be thought of as a linear combination of exponential decays, each with a single time constant ( $T_{2}$ value), for example,

$f(t)=\sum_{i}^{n} a_{i} e^{-t / T_{2 i}}$

where $a_{i}$ is the amplitude of the exponential and $n$ is the number of $T_{2}$ bins (Brownstein and Tarr, 1979; Walsh et al., 2013). In bNMR surveys of this type, it is assumed that surface relaxivity dominates the decay (neglecting the long decay of bulk water and strong magnetic gradient effects) and 
thus $T_{2}$ is inversely proportional to the pore geometry by

$$
\frac{1}{T_{2}} \approx \rho \frac{S}{V},
$$

where $S$ is the surface area of the pore, $V$ is the volume, and $\rho$ is surface relaxivity: a property of the surface to cause relaxation of the fluid (Kleinberg, 1996). Thus, Eq. (1) represents the decay from a distribution of pore geometries within a volume. For relatively simple pore geometries, $S / V$ is inversely proportional to size and so large pores result in long $T_{2}$ times.

Through regularized multiexponential fitting to the decay curve (Eq. 1), estimates of the total volumetric liquid water content and partial water contents as a function of pore size were constructed. Total volumetric water content is (with proper calibration) given by the initial amplitude of the multiexponential decay, while the estimates of volumetric water content as a function of pore size are derived from the integrated partial water contents as a function of $T_{2}$. Regularization was chosen through a manual search and found to be near optimal at the default values.

Models of water content at each depth can be concatenated to produce a plot of water saturation as a function of both depth and $T_{2}$, which is a linear function of pore size. The conversion of $T_{2}$ to pore size was not performed due to insufficient calibration data; however, relative relationships hold - the shorter the $T_{2}$, the smaller the effective pore size. Throughout this study, we refer to water as clay bound (referred to as bound for simplicity; $T_{2}$ less than $3.16 \mathrm{~ms}$ ), where water is bound to clay surfaces or otherwise in extremely tiny pore spaces; capillary bound ( $T_{2}$ between 3.16 and $31.6 \mathrm{~ms}$ ), where water is held by capillary forces in small pores; and mobile ( $T_{2}$ greater than $31.6 \mathrm{~ms}$ ). We note that these ranges are derived from oil-field NMR, and thus have limited application to the differing soils in this study; however, similar cutoffs have been used in environmental applications (e.g., Behroozmand et al., 2015; Knight et al., 2016). Moreover, the divisions are more of a gradient rather than a step function. We do, however, find the descriptions illustrative and therefore useful, and these $T_{2}$ divisions likely serve as a "lower bound" for the actual values. Analyses provided here are insensitive to small perturbations of these values. We refer the reader to (Pallatt and Thornly, 1990) for a full discussion on the divisions between bound, capillary, and mobile water. The boundaries are plotted on the model results as dashed lines for reference.

\section{Results}

In this section, we show an example of the NMR interpretations for a field site with an observation in both burned and unburned terrain. We then generalize the results through a statistical analysis of the total water content between frozen

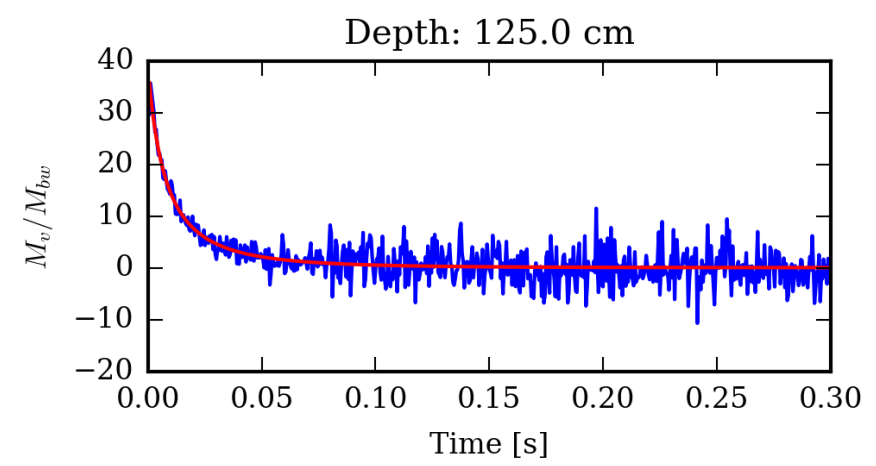

(a)

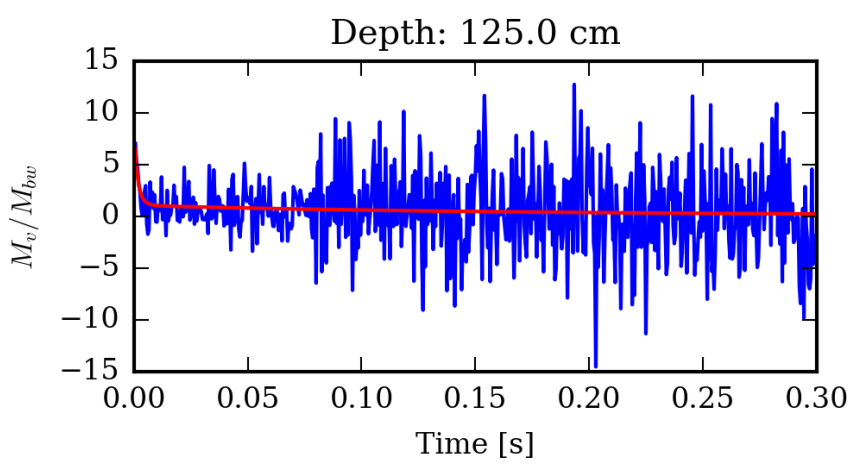

(b)

Figure 4. Example CPMG echo train envelope curves from AK204ROAD at $125 \mathrm{~cm}$ depth for unfrozen (a) and frozen (b) soils. Soil type is consistent across the plots. Vertical axis is in NMR response normalized by the calibration factor and is thus in units of percent water content. Red curve indicates the best multiexponential decay fit.

and unfrozen soils, as well as the apparent pore size distribution.

A single NMR dataset corresponds to the NMR signal at one depth in one borehole and is generally plotted as a stacked time-series decay; for the CPMG experiment, the time series represents the CPMG echo train envelope. Figure 4 shows the CPMG echo train envelope curve $\left(T_{2}\right.$ decay) for an example field site, AK204-ROAD, which contains data from both burned (Fig. 4a) and unburned (Fig. 4b) areas. Each plot is from the same soil type at the same depth below ground surface. The best-fitting multiexponential decay is superimposed (Eq. 1). Note the long, smooth decay exhibited by the unfrozen, saturated soil (Fig. 4a) in contrast to the rapid decay of tightly bound water exhibited by the frozen soil (Fig. 4b).

Figure 5 shows the calculated water contents from site AK204-ROAD as a function of pore size for both burned areas where near-surface permafrost had thawed (Fig. 5a) and unburned areas where permafrost remained intact (Fig. 5b). The left panel shows the relative amounts of bound, capillary-bound, and mobile liquid water as a function of 

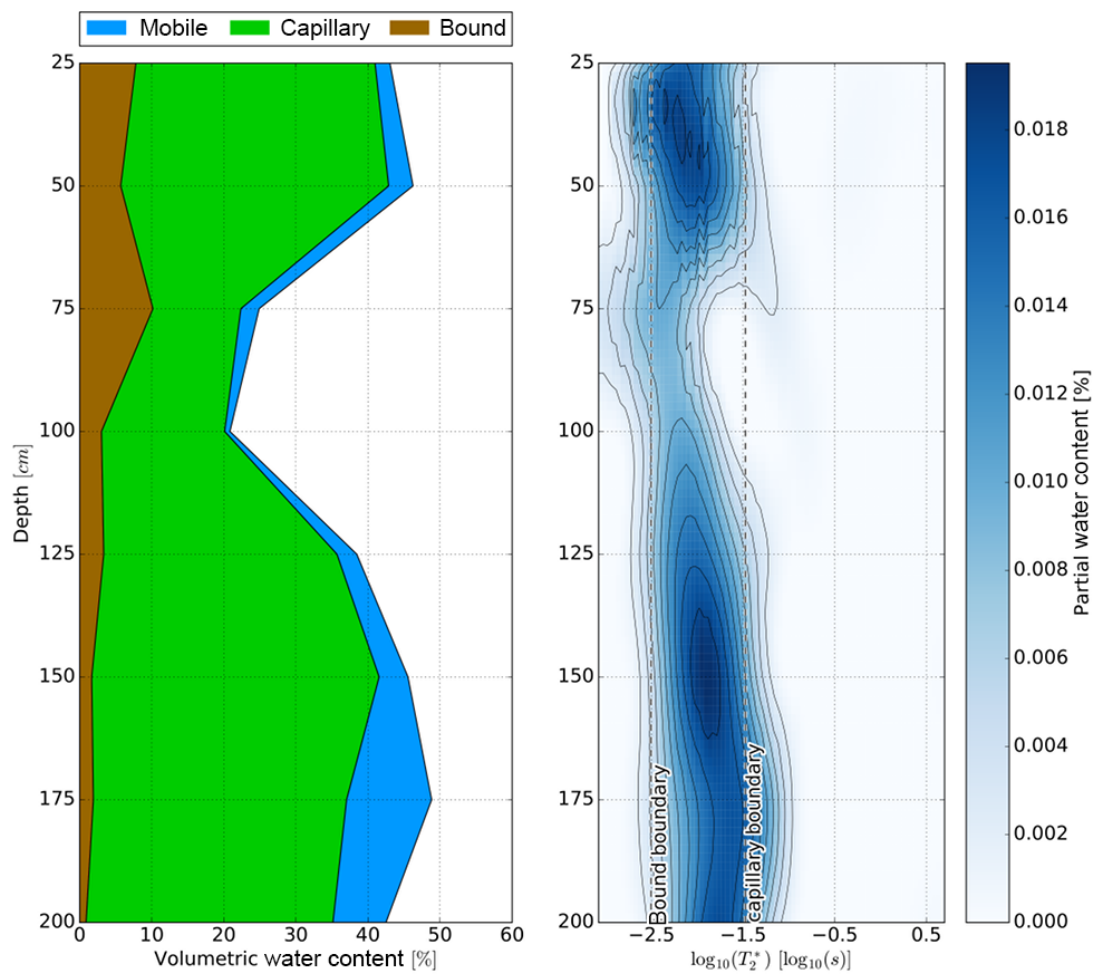

(a)
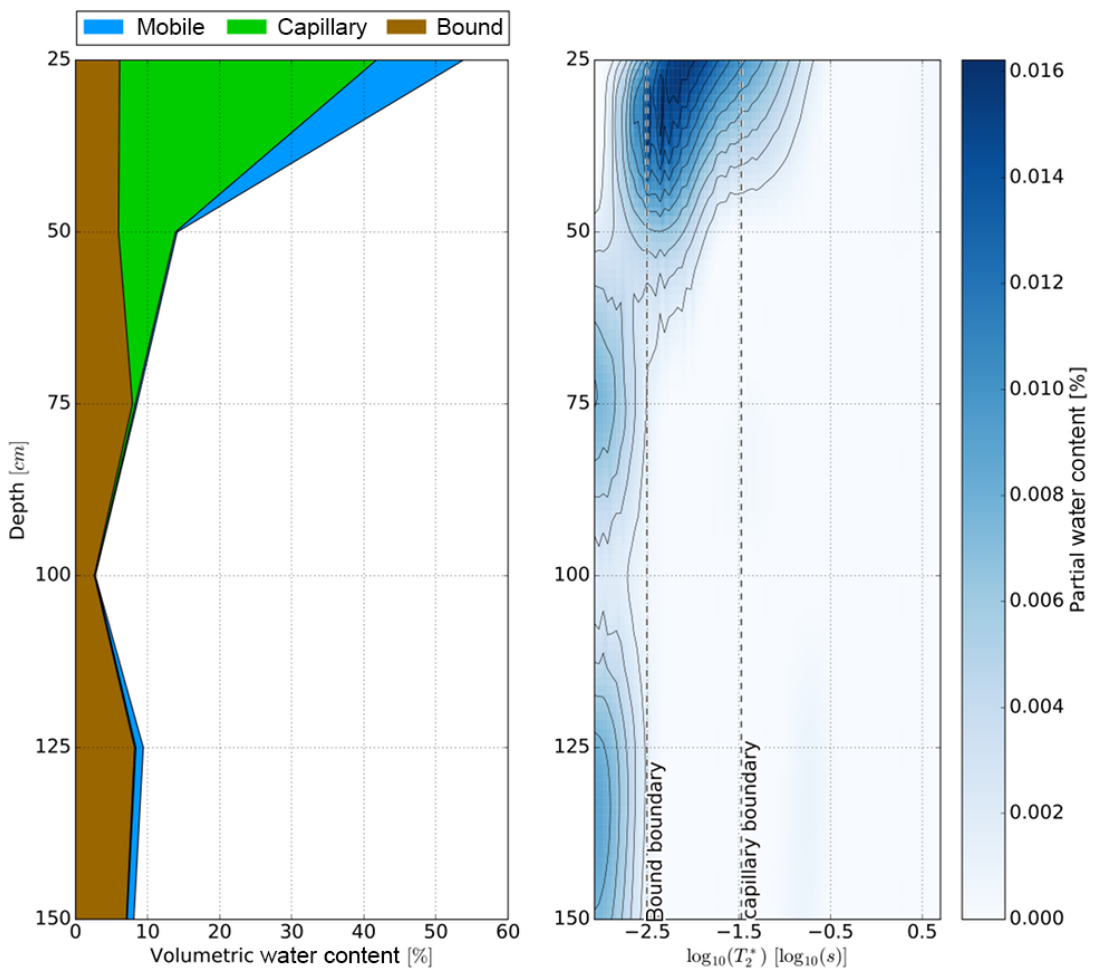

(b)

Figure 5. Model constructed for two boreholes at AK204-ROAD. (a) Unfrozen model. (b) Frozen model. Data were acquired at depths enumerated in each plot. Note the difference in vertical scale due to different borehole depths. 
Table 1. Number of observations for each soil type classified into frozen or unfrozen.

\begin{tabular}{lrr}
\hline & Frozen & Unfrozen \\
\hline Silty & 28 & 55 \\
Sandy & 2 & 28 \\
Peaty & 21 & 2 \\
Rocky & 6 & 3 \\
\hline
\end{tabular}

depth; the sum of those yields the total water content. The right panel shows the calculated $T_{2}$ distribution (linearly related to pore size) as a function of depth. Integrating across a depth from 0 to the bound limit yields the estimate of bound water. As in nature, the pore sizes generally demonstrate a log-normal distribution.

AK207-POLY is a tundra location dominated by ice wedge polygons. The computed model is shown in Fig. 6 . This site was particularly interesting as the borehole was drilled into an ice wedge. The near surface was oversaturated with standing water (due to the ice wedge acting as an aquitard) creating a slurry of fine silt. Beneath the thin active layer, the borehole was drilled into massive ice.

For statistical analysis, the results from each depth at each observation location were divided into the following categories: frozen or unfrozen; and silty, sandy, peaty, or rocky (Table 1). Results should not be treated as a random sampling of terrains; there is significant sampling bias present. It is difficult or impossible, for example, to drill through rocky terrain, and thus those locations are undersampled.

\subsection{Statistical analysis}

Based on the active layer thickness from permafrost probe measurements and the DC resistivity inversions along each transect, the recovered model parameters were sorted into frozen and unfrozen categories. We note the limited presence of seasonal frost in these datasets. Figure 7 shows a composite histogram for the total water contents of frozen and unfrozen soil. Figure 8 shows the same information displayed using a box-and-whisker plot. The box of the boxand-whisker plot represents the interquartile range (IQR), or the central $50 \%$ of the data, with the median shown as a horizontal line. The whiskers are defined as the extremes of the dataset, excluding those data points outside of 1.5 times the $\mathrm{IQR}$, or $99.3 \%$ of the data, which is equivalent to $2.698 \sigma$ (standard deviation). Outliers are plotted as pluses.

The soils without permafrost present show a mean water saturation of $38 \%(n=99)$ with a standard deviation of $14 \%$. Samples with permafrost present $(n=90)$ have a mean water saturation of $8 \%$ with a standard deviation of $6 \%$. Most of the large deviation in saturation is a consequence of the large variability in sandy soils.

Figure 9 shows how the aggregate-bound, capillary-bound, and mobile water contents change as a function of freez- ing, assuming similar soil types between the active layer and permafrost within each borehole. The samples of frozen and thawed measurements for clay, capillary, and mobile water were log-transformed (assuming a log-normal distribution) and each category was tested to see if the sample means between thawed and frozen were statistically different. Both a Student's $t$ test (assuming log-normality) and a Kolmogorov-Smirnov statistic (nonparametric) were used; both yielded equivalent results assuming the null hypothesis of equivalent distributions. As expected, water that is already bound to clay or other minerals with large surface area within the pore space is difficult to freeze and thus the values do not change significantly between frozen and thawed soils $(p>0.01)$. Conversely, the mobile water content is significantly reduced from thawed to frozen $(p<0.01)$, as is the capillary-bound water $(p<0.01)$, which is consistent with results from previous studies.

Figure 10 shows a box-and-whisker plot normalized by the total water content. In general, the $T_{2}$ values of the liquid water bound to pore surfaces remains largely unchanged, and thus the relative contribution of bound water to the total water is increased. The ratio of mobile water to total water remains relatively constant, however. This counterintuitive proportionality confirms the conclusions of previous laboratory analyses and modeling: ice nucleates in the center of pores, and liquid water remains in contact with rock or soil surfaces at the pore exterior (Anderson, 1967; Churaev et al., 1993; Kleinberg and Griffin, 2005). Based on these results, we concur with Kleinberg and Griffin (2005) that the water-soil NMR relaxation dominates the water-ice relaxation (thus the surface relaxivity for soil or rock as given in Eq. (2) is much larger than that of ice). $T_{2}$ values are proportional to the surface-area-to-volume ratio of the pore (rather than absolute pore volume); since the water-ice interface does not largely contribute to the surface area in terms of relaxation, the $T_{2}$ values are consistently reduced with increasing frozen water content.

\section{Soil freezing simulations}

We constructed a soil freezing simulation to test both the null hypothesis - that ice nucleates in the center - and an alternative - that ice coats pore walls and aggrades inwards. Understanding the distribution of the water and ice phases within the permafrost media has important hydrologic implications on fluid flow and thermal properties. Ice phase water contributes no measurable signal at the frequencies and field strengths encountered in bNMR. As such, interpretation of the data hinges on also understanding the missing ice signal. Numerical simulation provides a mechanism to explore possible distributions of ice and water phases within a pore matrix. The presence of ice will influence the signal, even though it is not directly contributing energy to the signal. One major source of this influence is that ice has a characteristi- 

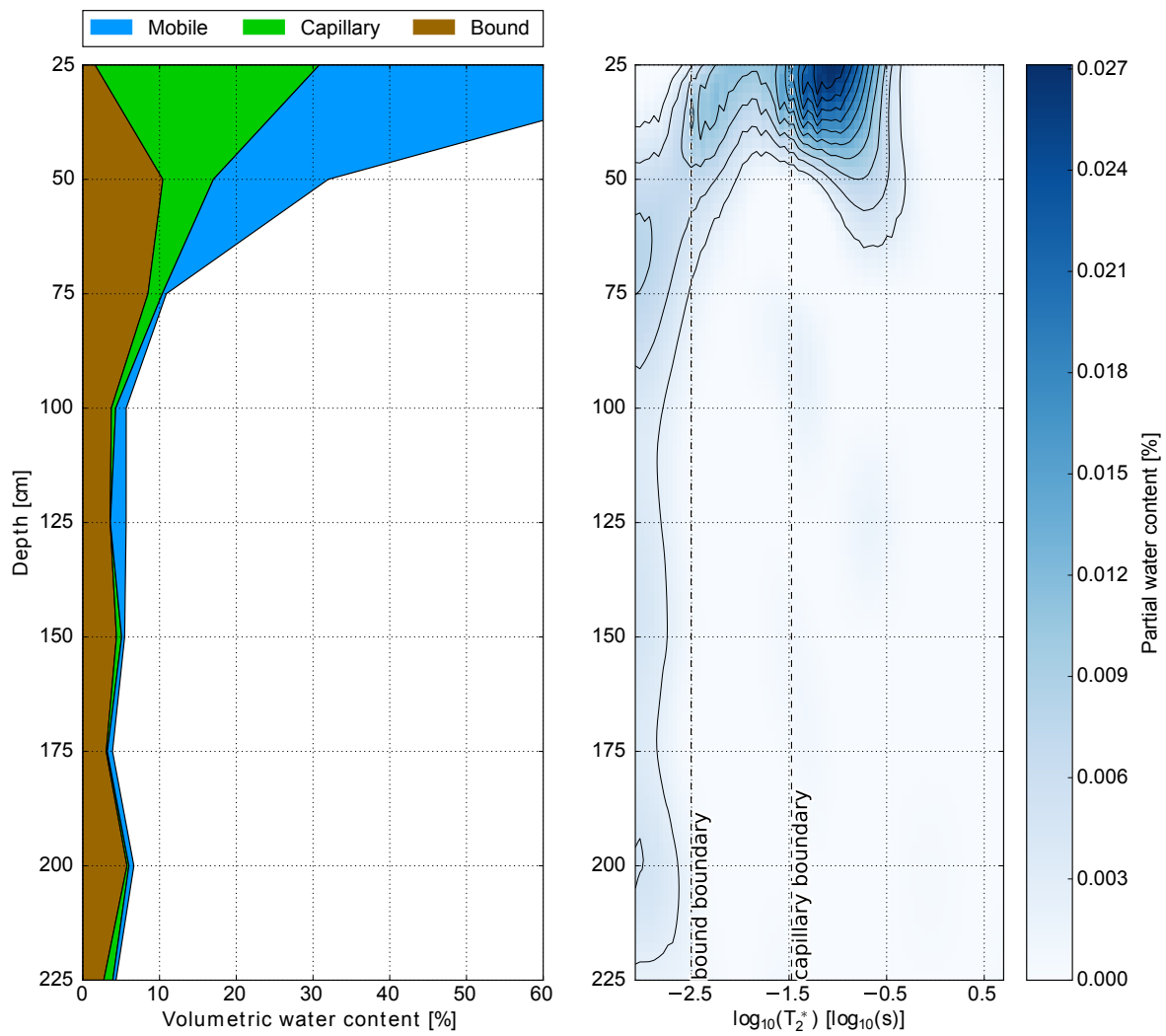

Figure 6. Model constructed from borehole measurements in an ice wedge at AK207-POLY. Data were acquired at depths enumerated on the plot.

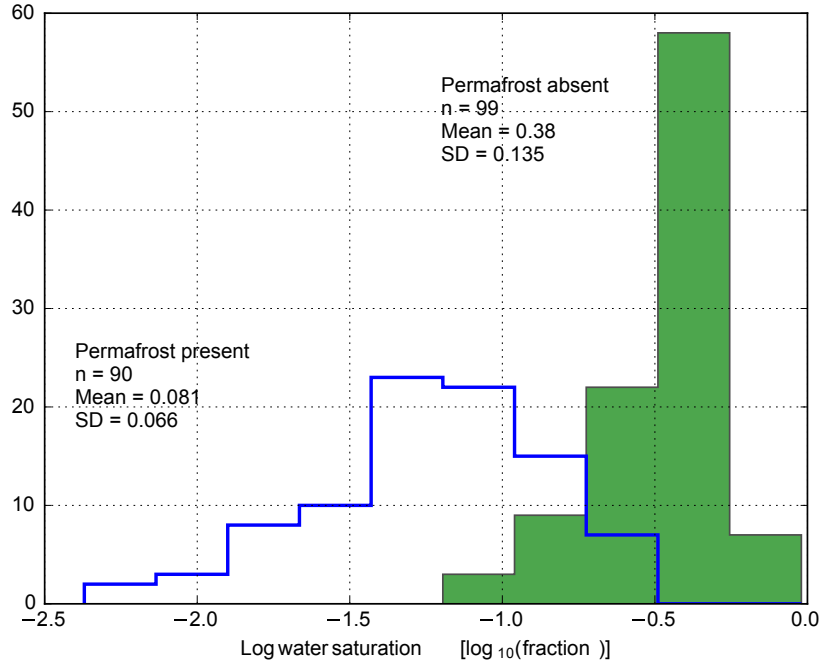

Figure 7. Histogram of bNMR results showing counts of total water content for data acquired in frozen zones (blue line) and unfrozen zones (green shaded). Measured water contents greater than $60 \%$ have been culled. Results are displayed on a logarithmic water saturation scale to easily view the distributions. cally low surface relaxivity $(\rho)$ value, and, depending on its location within a pore, it could substantially alter the relaxation rate of spins within pores. For instance, a thin layer of ice covering the grain surface within a pore could mask the surface relaxivity of the grain, increasing the relaxation time but having a minimal impact on the amplitude of the data. Conversely, ice within a pore will not mask the grain surface relaxivity and will therefore predominantly impact the signal amplitude. For this reason, empirically determined cutoff values for mobile, capillary-bound, and clay-bound water used in the oil and gas industry - and more recently applied in near-surface hydrology - may not be appropriate for interpreting these data. To better understand the controlling mechanism for signal decay, random walk simulations were performed using a suitable proxy model, with AK204-ROAD as a reference dataset.

A pore matrix model based on a thresholded $\mu \mathrm{CT}$ image of a silica gel was used as the starting point for an input model (Blunt et al., 2014; Dong and Blunt, 2009). A $(50 \times 50 \times 50)$ voxel subset was extracted with a porosity of $57 \%$ in order to correspond to the observed data, which showed early time intensities greater than $50 \%$ NMR water. The actual image was taken at a resolution of $3.85 \mu \mathrm{m}$; the resolution was scaled 


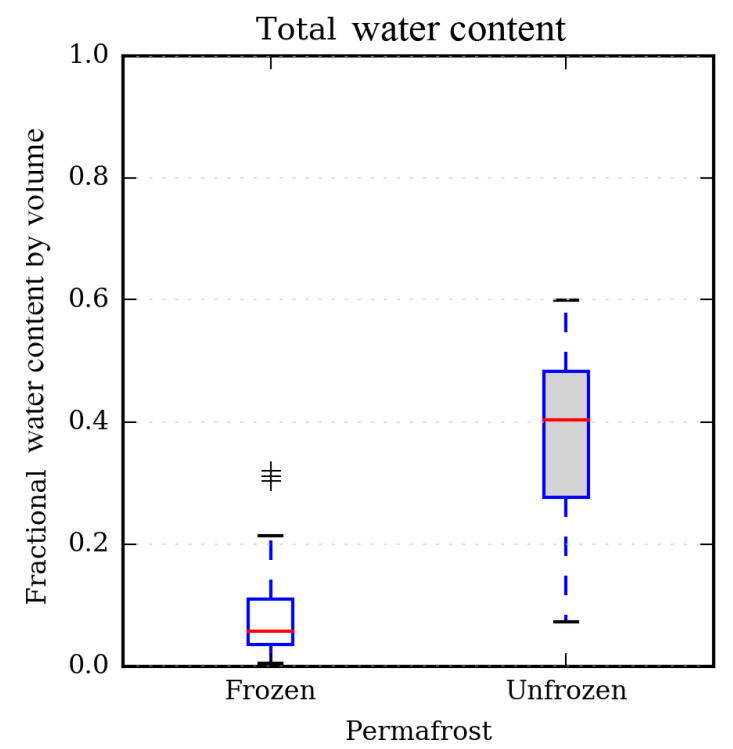

Figure 8. Box-and-whisker plot of total volumetric water content as a function of permafrost presence (frozen) or absence (unfrozen); active layer measurements are included in the unfrozen category. The box represents the interquartile range (IQR, or $50 \%$ of the data) with the whiskers defined as 1.5 times the IQR. Outliers are plotted as pluses; the line within the IQR represents the median.

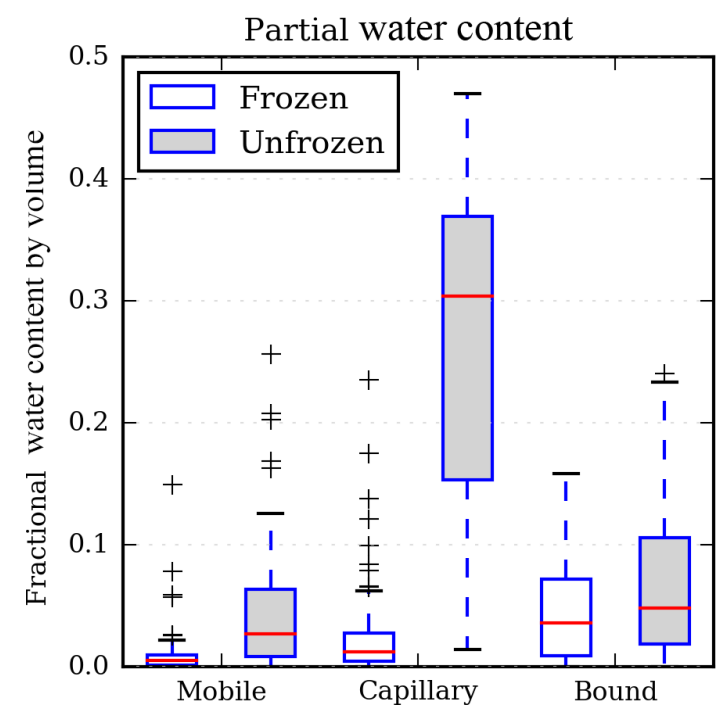

Figure 9. Box-and-whisker plot of partial volumetric water contents as a function of permafrost presence (frozen) or absence (unfrozen). Elements on the left of each pair correspond to the presence of permafrost; those on the right correspond to the absence of permafrost.

down to $2.2 \mu \mathrm{m}$ for simulations such that the grain matrix corresponded to silt grain sizes $(3.9-62.5 \mu \mathrm{m})$.

Random walk simulation code developed by the Imperial College London (Talabi et al., 2009) was used to perform synthetic NMR simulations on the developed model. The open source simulation code was modified to accommodate

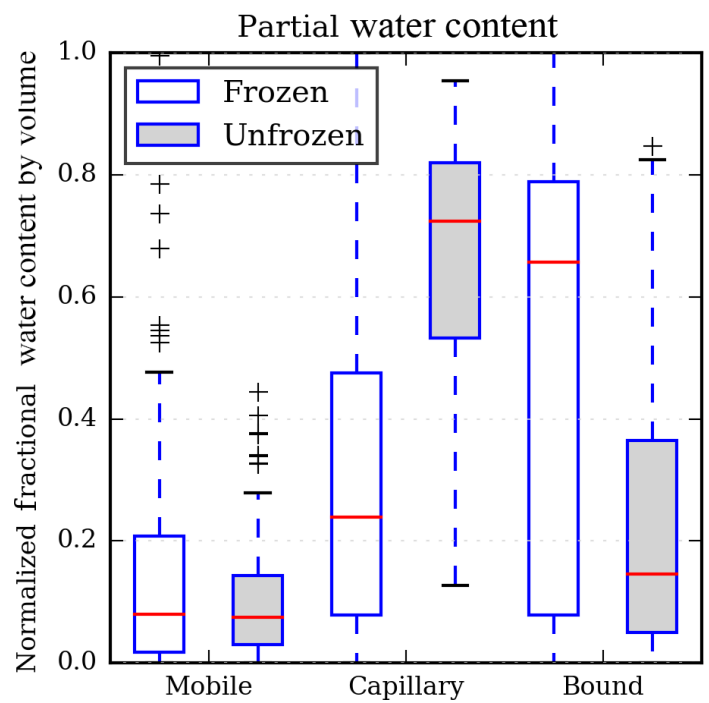

Figure 10. Box-and-whisker plot of partial volumetric water contents as a function of permafrost presence (frozen) or absence (unfrozen) normalized by total water content. Elements on the left of each pair correspond to the presence of permafrost; those on the right correspond to the absence of permafrost.

two different surface relaxivity values - for ice and silt portions of the grain matrix. Inputs to the simulations were chosen to approximate the Dart instrument, and field data from AK204-ROAD were used to calibrate simulation inputs.

To explore the possible distribution of water phases within the matrix a simplified conceptual freezing model was then developed, with $\rho_{\text {grain }}=9.5 \times 10^{-2}$ and $\rho_{\text {ice }}=2.0 \times$ $10^{-5} \mathrm{~m} \mathrm{~s}^{-1}$. The value of $\rho_{\text {grain }}$ was calibrated in order to fit the reference bNMR data, and the relaxivity of ice was set to be several orders of magnitude lower. Freezing was assumed to nucleate from pore centers, away from throats or pore walls. A suite of progressively more frozen models with ice propagating from the pore centers towards the walls was then developed to simulate stages of freezing-thawing. Figure 11 shows a cutaway for three stages of the freezing model. This model serves as a first-order approximation of the distribution of water and ice phases and is not intended to capture the dynamics of freezing comprehensively. Restricted diffusion within pore spaces due to an ice-water matrix would result in enhanced $T_{2}$ times, for example.

Figure 12 shows the predicted and measured NMR response for freezing models corresponding to 25, 50, and $75 \mathrm{~cm}$ depths at AK204-ROAD. Even though the model is simplified, the derived freezing model predicts the NMR response for frozen silts well. The experiment was conducted in reverse (available as Supplement), where ice nucleated on the surface of the pores and aggraded inwards; the simulated data were completely unable to fit the observed data. We therefore posit that the most likely distribution of phases is that of ice nucleating from the centers of pores. 


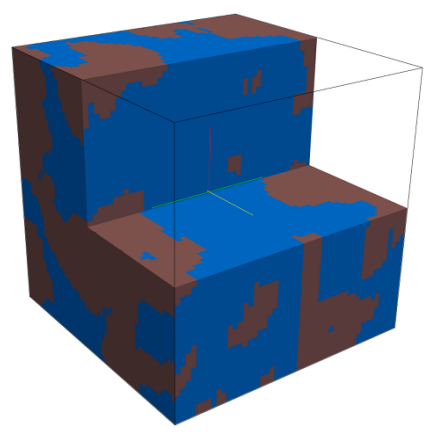

(a)

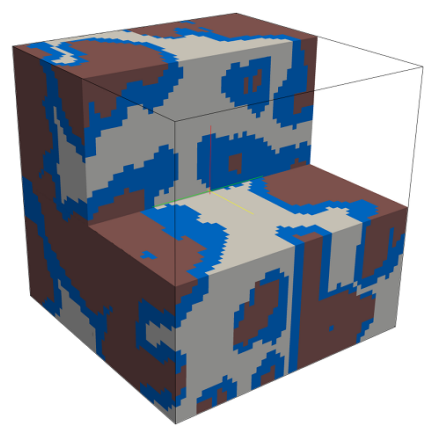

(b)

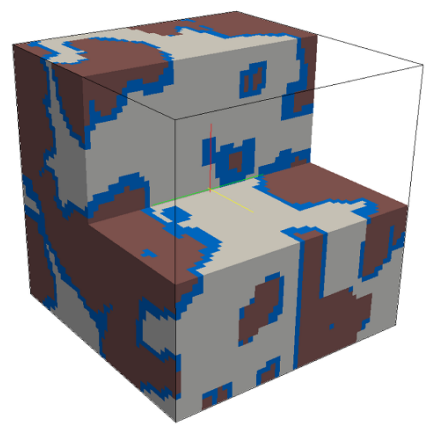

(c)

Figure 11. Soil freezing models for three progressive stages of freezing in pore spaces. Brown represents the silt, blue represents the liquid water, and white represents ice.

Implications of this include higher permeability than would be observed if the opposite were true. Additionally, for this reason, the NMR response of liquid phase water in partially frozen soils will be dominated by the sediment interactions. This finding supports the applicability of existing cutoff values for the interpretation of pore sizes and water content distribution in permafrost media.

\section{Discussion}

Frozen water has an exceptionally short NMR decay time - the hydrogen (being bound in a crystal lattice) dephases almost immediately, which is well within the "dead time" of the instrument (between the transmitter shut-off time and the receiver turn-on time). Thus, Figs. 7 and 8 indicate only liquid water. The results are as expected - when data are aggregated over all soil types, there is a clear separation in the histogram between liquid water present in unfrozen and frozen soils. This separation is not complete, however, because warm permafrost contains significant liquid water, even in the larger pores.

Characteristic freezing curves constructed by Williams and Smith (1989) indicate that clay-bound water can remain $20 \%$ liquid down to $-5^{\circ} \mathrm{C}$. Measurements by Romanovsky and Osterkamp (2000) show between approximately 2 and

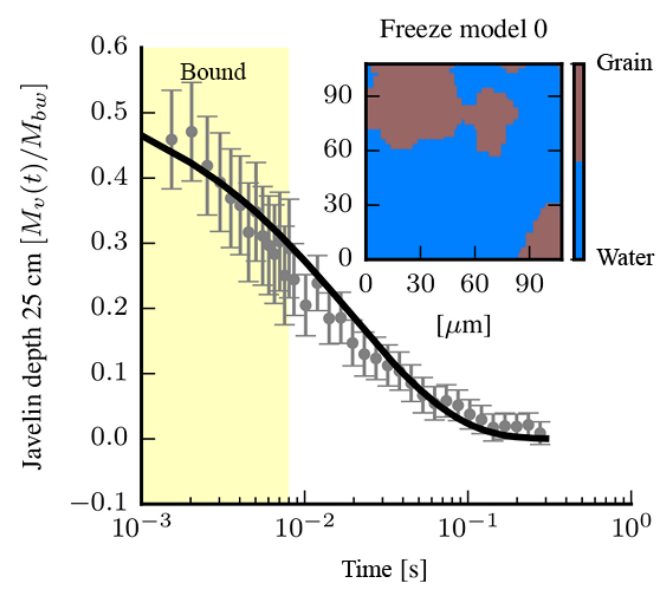

(a)

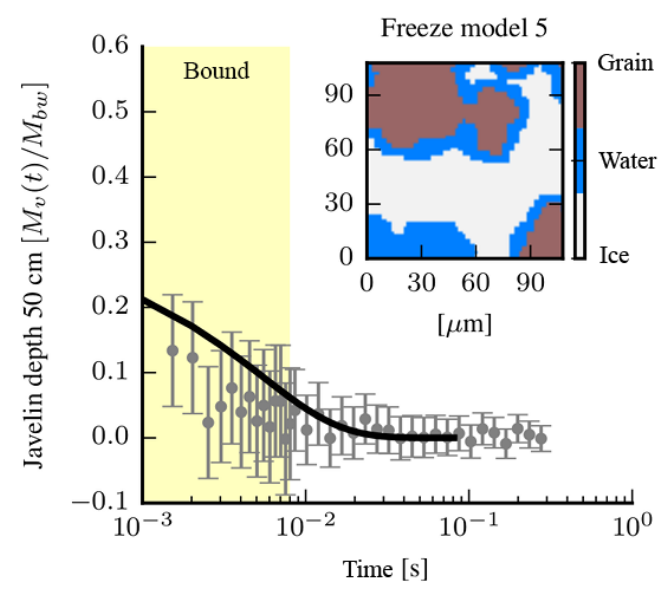

(b)

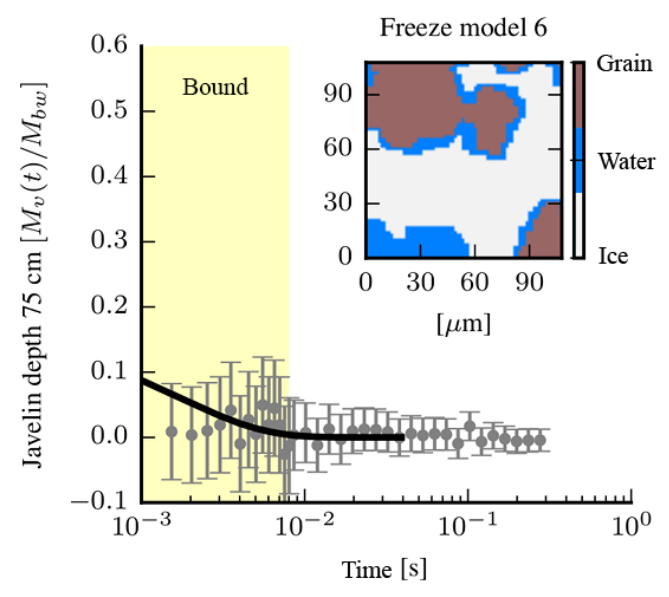

(c)

Figure 12. Observed (points) and predicted (line) data for progressively frozen models, corresponding to progressive depths in AK204-ROAD. 
$9 \%$ unfrozen water by volume (at $-5^{\circ} \mathrm{C}$ ) depending on sample location, including a somewhat spatially coincident measurement at AK212-LTER. The comparison of the results between the two studies (known as Bonanza Creek in the comparison study) indicates the permafrost measured at $1 \mathrm{~m}$ depth had a calculated temperature of between -1 and $-2{ }^{\circ} \mathrm{C}$ at the time of the bNMR measurement.

The consistency between borehole and laboratory observations seen in both the statistical analyses of field data and the freezing simulations provides good evidence that studying the NMR response of the core is, in fact, a good proxy for in situ measurements. Thus, the bNMR and core analyses are complementary; bNMR can provide good spatial coverage and access at low cost while core analyses can provide further detail and calibration between $T_{2}$ and pore size.

Though not the main focus of this study, it may be of interest to note the distribution of frozen-unfrozen soil as a function of soil type (Table 1). Though the choice of soil type exhibits significant sampling bias, the relative abundances of frozen versus unfrozen soil within each bin can be investigated. Peat is a phenomenal insulator, and therefore there are few sampled unfrozen peaty points. Conversely, not only does sandy soil have a higher bulk thermal conductivity (Konavalov and Romain, 1973) and thus thicker active layer, but it is also more difficult to retain water in the near surface due to higher permeability.

We note that we assume a consistent pore shape throughout these investigations. As current NMR instrumentation is generally insensitive to the majority of clay-bound water $\left(T_{2}<3.6 \mathrm{~ms}\right)$, the distorted surface-area-to-volume ratio of clay minerals does not affect the interpretation of these data, and we find this assumption valid. Additionally, the soils in this investigation precluded significant proportions of clay. However, as dead times improve with newer generation instrumentation, the plate-like nature of clay minerals and thus the changed geometrical distribution of unfrozen water in permafrost (Akagawa and Syouji, 2004) will necessitate commensurately improved interpretation methods. For example, (Knight et al., 2016) and (Xiao et al., 2012) demonstrate the capability of NMR to provide reliable estimates in clay and tight oil and gas reservoirs with similar partial and corresponding surface-area-to-volume ratios with appropriate calibration of the coefficients in Timur-Coates and Schlumberger-Doll equations (if converting to absolute pore sizes and permeabilities).

\subsection{Error analysis}

Total water content is directly given by the initial amplitude of the decay curve. Analysis of the stacked data yields error estimates of the total volumetric water content between 2 and $10 \%$ depending on location.

The error in $T_{2}$ estimates is less straightforward. Inspection of Fig. 4 yields an obvious dependence of the error level on the amount of volumetric water. Low amplitudes and rapid decays result in fewer measurements in the time series available for an exponential fit, and the process becomes unstable. This instability can be controlled with regularization but still contributes fundamental uncertainty in the final model. Techniques such as Bayesian analysis may help elucidate the contributions of the short decays to uncertainty.

\section{Conclusions}

Borehole nuclear magnetic resonance is a rapid and reliable way to characterize the hydrologic properties of nearsurface permafrost and active layer water. Boreholes constructed with hand- or small gasoline-powered augers as well as larger Geoprobes can be logged with minimal concern for the disruption of permafrost. Borehole NMR successfully measures the significant liquid water present in warm permafrost while allowing for detailed analysis of pore size distribution as a function of depth.

Both in situ NMR measurements and soil freezing models agree with the hypothesis that ice nucleates in the center of pores in soil matrices. Statistical analyses of the NMR data are consistent with a low-relaxivity ice aggrading from the interior. Numerical simulations demonstrate the sensitivity of borehole NMR to this mechanism of ice formation by modeling a central nucleation as well as a pore-wall aggradation; ice formation from the pore wall is unable to fit the observed data, while central nucleation matches well.

The relative ease with which these measurements can be made allows for large spatial areas to be investigated, helping to understand the effects of climate change and increased impacts of wildfires on near-surface permafrost. Permanent boreholes can allow for monitoring of permafrost conditions on a variety of timescales, from daily to decadal. When combined with other data, such as hydrologic, geologic, and geophysical, the NMR technique fills an important gap in understanding complex changes in permafrost environments.

Code availability. Random walk code from the Imperial College London is available at http://www3.imperial.ac.uk/pls/portallive/ docs/1/50289716.ZIP.

Data availability. All data are freely available and archived with Science Base (Minsley et al., 2016a) and conform to federal data release standards.

\section{The Supplement related to this article is available online} at https://doi.org/10.5194/tc-11-2943-2017-supplement.

Competing interests. The authors declare that they have no conflict of interest. 
Disclaimer. Any use of trade, firm, or product names is for descriptive purposes only and does not imply endorsement by the US Government.

Acknowledgements. We thank Amy Marsh for invaluable field help and joviality. We also thank Elliot Grunewald and Dave Walsh of Vista Clara, Inc. and Tony Wong of the University of Colorado for numerous helpful discussions. Research was funded by the US Geological Survey (USGS) Land Change Science Program's LandCarbon project (Z. Zhu, project chief). A portion of this work was performed under USGS contract G08PC91508. Additional funding was provided by the Changing Arctic Ecosystems Initiative of the USGS Ecosystems Mission Area through the Alaska Cooperative Fish and Wildlife Research Unit. The Bonanza Creek Long-Term Ecological Research Program and Institute of Arctic Biology's Toolik Field Station provided in-kind support and access to their research sites. We thank Art Gelvin of the Cold Regions Research and Engineering Laboratory, Army Corps of Engineers, for access to the CCHRC borehole sites.

Edited by: Stephan Gruber

Reviewed by: Satoshi Akagawa and one anonymous referee

\section{References}

Akagawa, S. and Syouji, H.: Relation between $T_{2}$ of pulse NMR and unfrozen water thickness, in: Proceedings of Hokkaido Branch of Japanese Geotechnical Society, Sapporo, Japan, 75-78, 2004 (in Japanese).

Anderson, D.: Ice nucleation and the substrate-ice interface, Nature, 216, 563-566, https://doi.org/10.1038/216563a0, 1967.

Behroozmand, A. A., Keating, K., and Auken, E.: A Review of the Principles and Applications of the NMR Technique for Near-Surface Characterization, Surv. Geophys., 36, 27-85, https://doi.org/10.1007/s10712-014-9304-0, 2015.

Blunt, M. et al.: A1 synthetic silica $\mu \mathrm{CT}$ image, imperial College Consortium on Pore-scale Modelling, https://doi.org/10.6084/m9.figshare.1189255.v1, 2014.

Brown, J., Jorgenson, M., Smith, O., and Lee, W.: Long-term rates of coastal erosion and carbon input, Elson Lagoon, Barrow, Alaska, in: Eighth International Conference on Permafrost, Balkema Publishers, Zurich, Switzerland, 101-106, 2003.

Brownstein, K. and Tarr, C.: Importance of classical diffusion in NMR studies of water in biological cells, Phys. Rev. A, 19, 24462453, 1979.

Churaev, N., Bardasov, S., and Sobolev, V.: On the non-freezing water interlayers between ice and a silica surface, Colloid. Surface. A, 79, 11-24, https://doi.org/10.1016/0927-7757(93)80155-8, 1993.

Davis, N.: Permafrost, a guide to frozen ground in transition, U. of Alaska Press, Fairbanks, AK, 2001.

Dong, H. and Blunt, M. J.: Pore-network extraction from microcomputerized-tomography images, Phys. Rev. E, 80, 036307, https://doi.org/10.1103/PhysRevE.80.036307, 2009.

Henry, K. and Smith, M.: A model-based map of ground temperatures for the permafrost regions of Canada, Permafrost Periglac., 12, 389-398, https://doi.org/10.1002/ppp.399, 2001.
Hinzman, L., Bettez, N., Bolton, W., et al.: Evidence and implications of recent climate change in northern Alaska and other arctic regions, Climatic Change, 72, 251-298, https://doi.org/10.1007/s10584-005-5352-2, 2005.

Hugelius, G., Strauss, J., Zubrzycki, S., Hardin, J., Schuur, E., Ping, C.-L., Schirrmeister, L., Grosse, G., Michaelson, G., Koven, C., O’Donnell, J., Elberling, B., Mishra, U., Camill, P., Yu, Z., Palmtag, J., and Kuhry, P.: Estimated stocks of circumpolar permafrost carbon with quantified uncertainty ranges and identified data gaps, Biogeosciences, 11, 6573-6593, https://doi.org/10.5194/bg-11-6573-2014, 2014.

Jorgenson, M., Romanovsky, V., Harden, J., Shur, Y., O’Donnell, J., Schuur, E., Kanevskiy, M., and Marchenko, S.: Resilience and vulnerability of permafrost to climate change, Can. J. Forest Res., 40, 1219-1236, https://doi.org/10.1139/X10-060, 2010.

Jorgenson, M., Harden, J., Kanevskiy, M., O’Donnell, J., Wickland, K., Eqing, S., Manies, K., Zhuang, Q., Shur, Y., Striegl, R., and Koch, J.: Reorganization of vegetation, hydrology and soil carbon after permafrost degradation across heterogeneous boreal landscapes, Environ. Res. Lett., 8, https://doi.org/10.1088/17489326/8/3/035017, 2013.

Kenyon, W.: Petrophysical principles of applications of NMR logging, The Log Analyst, 38, 21-43, 1997.

Kleinberg, R.: Utility of NMR $T_{2}$ distributions, connection with capillary pressure, clay effect, and determination of the surface relaxivity parameter $\rho_{2}$, Magn. Reson. Imaging, 14, 761-767, 1996.

Kleinberg, R. and Griffin, D.: NMR measurements of permafrost: unfrozen water assay, pore-scale distribution of ice, and hydraulic permeability of sediments, Cold Reg. Sci. Technol., 45, 63-77, https://doi.org/10.1016/j.coldregions.2004.12.002, 2005.

Knight, R., Grunewald, E., Irons, T., Dlubac, K., Song, Y., Bachman, H. N., Grau, B., Walsh, D., Abraham, J. D., and Cannia, J.: Field experiment provides ground truth for surface nuclear magnetic resonance measurement, Gephys. Res. Lett., 39, L03304, https://doi.org/10.1029/2011GL050167, 2012.

Knight, R., Walsh, D. O., Butler, J. J., Grunewald, E., Liu, G., Parsekian, A. D., Reboulet, E. C., Knobbe, S., and Barrows, M.: NMR Logging to Estimate Hydraulic Conductivity in Unconsolidated Aquifers, Groundwater, 54, 104-114, https://doi.org/10.1111/gwat.12324, 2016.

Konavalov, A. and Romain, L.: The thermophysical properties of peat soils, Soil Mech. Found. Eng., 10, 179-181, https://doi.org/10.1007/BF01706681, 1973.

Kuroda, T.: Theoretical study of frost heaving - Kinetic processes at water layer between ice lens and soil particles, in: Proceedings of the 4th International Symposium on Ground Freezing, Sapporo, Japan, 39-45, 1985.

Lara, M., Genet, H., McGuire, A., Euskirchen, E., Zhang, Y., Brown, D., Jorgenson, M., Romanovsky, V., Breen, A., and Bolton, W.: Thermokarst rates intensify due to climate change and forest fragmentation in an Alaskan boreal forest lowland, Glob. Change Biol., 22, 816-829, https://doi.org/10.1111/gcb.13124, 2016.

Legchenko, A., Baltassat, J.-M., Bobachev, A., Martin, C., Robain, H., and Vouillamoz, J.-M.: Magnetic resonance sounding applied to aquifer characterization, Ground Water, 42, 363-373, 2004. 
Meiboom, S. and Gill, D.: Modified spin-echo method for measuring nuclear relaxation times, Rev. Sci. Instrum., 29, 688-691, https://doi.org/10.1063/1.1716296, 1958.

Minsley, B., Pastick, N., Wylie, B., Brown, D., and Kass, M.: Fire impacts on permafrost in Alaska: Geophysical and other field data collected in 2014, Data release, US Geological Survey, https://doi.org/10.5066/F7959FM0, 2016a.

Minsley, B., Pastick, N., Wylie, B., Brown, D., and Kass, M.: Evidence for nonuniform permafrost degradation after fire in boreal landscapes, J. Geophys. Res., 121, 320-355, https://doi.org/10.1002/2015JF003781, 2016b.

Osterkamp, T., Viereck, L., Shur, Y., Jorgenson, M., Racine, C., Doyle, A., and Boone, R.: Observations of thermokarst in boreal forests in Alaska, Arct. Antarct. Alp. Res., 32, 303-315, https://doi.org/10.2307/1552529, 2000.

Pallatt, N. and Thornly, D.: The role of bound water and capillary water in the evaluation of porosity in reservoir rocks, in: First Society of Core Analysis European Core Analysis Symposium, London, UK, 223-238, 1990.

Parsekian, A., Dlubac, K., Grunewald, E., Butler, J., Knight, R., and Walsh, D.: Bootstrap Calibration and Uncertainty Estimation of Downhole NMR Hydraulic Conductivity Estimates in an Unconsolidated Aquifer, Groundwater, 53, 111-121, https://doi.org/10.1111/gwat.12165, 2015.

Parsekian, A. D., Grosse, G., Walbrecker, J. O., Müller-Petke, M., Keating, K., Liu, L., Jones, B. M., and Knight, R.: Detecting unfrozen sediments below thermokarst lakes with surface nuclear magnetic resonance, Geophys. Res. Lett., 40, 535-540, https://doi.org/10.1002/grl.50137, 2013.

Pastick, N., Jorgenson, M., Wylie, B., Nield, S., Johnson, K., and Finley, A.: Distribution of near-surface permafrost in Alaska: Estimates of present and future conditions, Remote Sens. Environ., 168, 301-315, https://doi.org/10.1016/j.rse.2015.07.019, 2015.

Romanovsky, V. and Osterkamp, T.: Effects of unfrozen water on heat and mass transport processes in the active layer and permafrost, Permafrost Periglac., 11, 219-239, https://doi.org/10.1002/1099-1530(200007/09)11:3<219::AIDPPP352>3.0.CO;2-7, 2000.

Schuur, E., McGuire, A., Schädel, C., Grosse, G., Harden, J., Hayes, D., Hugelius, G., Koven, C., Kuhry, P., Lawrence, D., Natali, S., Olefeldt, D., Romanovsky, V., Schaefer, K., Turetsky, M., Treat, C., and Vonk, J.: Climate change and the permafrost carbon feedback, Nature, 521, 171-179, https://doi.org/10.1038/nature14338, 2015.

Song, Y.: Recent Progress of Nuclear Magnetic Resonance Applications in Sandstones and Carbonate Rocks, Vadose Zone J., 9, 828-834, https://doi.org/10.2136/vzj2009.0171, 2010.

Sparrman, T., Öquist, M., Klemedtsson, L., Schleucher, J., and Nilsson, M.: Quantifying unfrozen water in frozen soil by high-field ${ }^{2} \mathrm{H}$ NMR, Environ. Sci. Technol., 38, 5420-5425, https://doi.org/10.1021/es0493695, 2004.
Talabi, O. A.: Pore-scale simulation of NMR response in porus media, PhD dissertation, Department of Earth Science and Engineering, Imperial College London, available at: http://www. imperial.ac.uk/earth-science/research/research-groups/perm/ research/pore-scale-modelling/software/nmr-simulation-codes/, 2008.

Talabi, O., AlSayari, S., Iglauer, S., and Blunt, M. J.: Pore-scale simulation of NMR response, J. Petrol. Sci. Eng., 67, 168-178, https://doi.org/10.1016/j.petrol.2009.05.013, 2009.

Tarnocai, C., Canadell, J., Schuur, E., Kuhry, P., Mazhitova, G., and Zimov, S.: Soil organic carbon pools in the northern circumpolar permafrost region, Global Biogeochem. Cy., 23, 1-11, https://doi.org/10.1029/2008GB003327, 2009.

Walsh, D., Turner, P., Grunewald, E., Zhang, H., Butler Jr., J., Reboulet, E., Knobbe, S., Christy, T., Lane Jr., J., Johnson, C., Munday, T., and Fitzpatrick, A.: A small-diameter NMR logging tool for groundwater investigations, Groundwater, 51, 914-926, https://doi.org/10.1111/gwat.12024, 2013.

Walsh, D., Grunewald, E., Turner, P., Hinnell, A., and Ferre, T.: Surface NMR instrumentation and methods for detecting and characterizing water in the vadose zone, Near Surf. Geophys., 12, 103-111, https://doi.org/10.3997/1873-0604.2013066, 2014.

Watanabe, K. and Mizoguchi, M.: Amount of unfrozen water in frozen porus media saturated with solution, Cold Reg. Sci. Technol., 34, 103-110, https://doi.org/10.1016/S0165232X(01)00063-5, 2002.

Watanabe, K. and Wake, T.: Measurement of unfrozen water content and relative permittivity of frozen unsaturated soil using NMR and TDR, Cold Reg. Sci. Technol., 59, 34-41, https://doi.org/10.1016/j.coldregions.2009.05.011, 2009.

Williams, P.: Unfrozen water content of frozen soils and soil moisture suction, Géotechnique, 14, 231-246, https://doi.org/10.1680/geot.1964.14.3.231, 1964.

Williams, P. and Smith, M.: The frozen Earth, Cambridge University Press, Cambridge, UK, 1989.

Xiao, L., Qiang Mao, Z., Nian Wang, Z., and Jin, Y.: Application of NMR logs in tight gas reservoirs for formation evaluation: A case study of Sichuan basin in China, J. Petrol. Sci. Eng., 81, 182-195, https://doi.org/10.1016/j.petrol.2011.12.025, 2012.

Yoshikawa, K. and Hinzman, L.: Shrinking thermokarst ponds and groundwater dynamics in discontinuous permafrost near Council, Alaska, Permafrost Periglac., 14, 151-160, https://doi.org/10.1002/ppp.451, 2003.

Zhang, T., Barry, R., Knowles, K., Heginbottom, J., and Brown, J.: Statistics and characteristics of permafrost and ground-ice distribution in the Northern Hemisphere, Polar Geography, 23, 132 154, https://doi.org/10.1080/10889379909377670, 1999.

Zimov, S., Davydov, S. P., Zimova, G., Davydova, A., Schuur, E., Dutta, K., and Chapin, F.: Permafrost carbon: stock and decomposability of a globally dignificant carbon pool, Geophys. Res. Lett., 33, L20502, https://doi.org/10.1029/2006GL027484, 2006. 